\title{
Working with mentally ill homeless persons: should we respect their quest for anonymity?
}

Yuval Melamed, Dafna Fromer, Ziona Kemelman and Yoram Barak Abarbanel Mental Health Centre, Bat Yam, Israel, Tel Aviv University, Tel Aviv, Israel and the Department of Social Services, Tel Aviv Municipality, Tel Aviv, Israel

\begin{abstract}
In recent years, the homeless population has received much attention as authorities attempt to comprehend this phenomenon and offer solutions. When striving to establish a relationship with the homeless person, many problems arise. We encounter this dilemma when respecting the right of the mentally ill to dwell neglected in the streets and simultaneously observe their inability to comprehend provisions such as housing, shelter, medical and mental care which contribute to their human dignity. The polarities of autonomy versus involuntary treatment are highlighted when treating the homeless population.

(Fournal of Medical Ethics 2000;26:175-178)

Keywords: Homelessness; involuntary treatment; autonomy
\end{abstract}

In recent years, the homeless population ${ }^{1}$ has received much attention, with attempts to organise and classify their problems and treat them within a community setting framework. Treatment includes identifying the client's needs, which could range from his or her mental and general health, substance abuse related disorders, public financial support, dental care, employment, housing assistance and support. ${ }^{2}$ Frequently there is a pressing need to provide accommodation in temporary shelters, hotels or even rental apartments. For this reason, cooperation between the psychiatrist, the social agency and the homeless person is essential. Conceptualising the homeless as clients, recognises that they might need different psychiatric services than other mentally ill subjects, ${ }^{3}$ and also recognises that it is not always possible to help them acknowledge their need of certain facilities, such as stable housing. ${ }^{4}$

Lack of interest, suspicion and cognitive dysfunction due to mental illness may make it difficult to achieve cooperation with these patients. Homelessness and mental illness are related ${ }^{56}$ but the problem of cooperation exists among all groups of homeless populations, regardless of mental illness. The homeless have similar biographical and demographic profiles, ${ }^{7}$ regardless of co-existing mental disorders.

Hamid et $a l^{8}$ argued that homelessness is due to the lack of housing provisions to the poorest sectors of society and that there is an overestimation of their level of psychiatric morbidity. Today, there is a tendency to avoid hospitalisation whenever possible by considering the rights and autonomy of the mentally ill $^{9}$ even as far as accepting their right to refuse treatment. ${ }^{10}$ Progress in dealing with this problem is essential in the setting of the homeless. A meeting should be arranged between the homeless person and the psychiatrist in order to establish contact and eventually offer treatment.

The psychiatrist feels responsible for the mentally ill person. He must invest considerable time in establishing a relationship, and thus this becomes an extended process. Without a precise examination, there is the danger that the mentally ill patients will not receive appropriate treatment. A distinction exists between a mentally ill person, incapable of caring for his needs, which leads to his homelessness and other individuals who do not suffer from severe psychopathology.

Tel Aviv is Israel's largest urban centre, with a population of some $1,000,000$ people. There is a specialised unit consisting of social workers and psychiatrists who assist the homeless, treating approximately 150 subjects annually. The homeless person's relationship with the therapist is different from the usual therapist-patient relationship. It might start with a note left on the homeless person's park bench, inviting him to visit the unit offices. It may also include an attempt to initiate a conversation with him in the park, in an apartment building entrance or any other place where the homeless are found.

After this first step is taken, the homeless person is given a full psychiatric examination. Those not 
requiring psychiatric hospitalisation are provided with food and blankets by the social agency, offered immediate temporary shelter and help to return to their family or find permanent housing, and to claim social security. Information concerning their past and families may be gleaned from conversations with them. This may be used to establish a link with those from their past and to bridge the gap between them. The more the person has "distanced himself" from ordinary life, the more difficult it is to reach him. At times, it is impossible.

Many of the homeless do not seek help. Whose responsibility is it? Should the authorities make the necessary efforts to engage homeless people in conversation and treatment or should the homeless be responsible for their own care?

At this first stage, our efforts were often thwarted, raising the controversy of autonomy versus paternalism when approaching the homeless. The following are case descriptions illuminating this problem.

\section{Case descriptions}

CASE 1

Mr X, a 40-year-old male, lived for a long time in a public park in the city. He habitually arrived at 6:00 pm, laid down on the bench and covered himself entirely from head to toe with his jacket. His clothes were dirty and frayed. His hair and beard were unkempt and a foul odour emanated from beneath his oversized old jacket. He waved away all attempts to hold a conversation with him with a motion indicating "go away". When asked specific questions, he said he wanted absolutely nothing but to be left alone.

He would not give his name or the name of any relative. In repeated attempts at conversation with him or other "neighbours" in the park, it was impossible to glean any information, except for the fact that he arrived in the evening and remained in the park the entire night, did not speak with anybody and left early in the morning. No one had any idea where he went during the day or how he subsisted. Since there was no name or identity number, we were unable to locate any family or information about his past.

CASE 2

Mr Y rides his bicycle around the metropolitan area all day and all night. His filthy clothes, dishevelled hair and long beard distinguish him from an ordinary cyclist. He appears estranged and detached from society. His bicycle carrybaskets are brimming over with old, apparently useless, objects such as pots, cartons and many bags. The bike was often left standing at the side of the road; it seeemed likely that he had gone to sleep among the roadside bushes.

It was impossible to establish a relationship with Mr Y. When a car stopped or passed nearby, he immediately got on his bicycle and continued on his way. He seemed to be on a long, endless journey, day and night, regardless of rain or summer's heat.

CASE 3

$\mathrm{Mr} \mathrm{Z}$ was brought to a psychiatric emergency room by the police after he had spent many hours in the park during a rainy, cold night. He refused to undergo any social intervention or identify himself. After observing him for a long period of time, the police became concerned. They brought him in on a particularly cold night. In the emergency room, he refused to identify himself or cooperate. After many hours, a veteran staff member remembered that he had been previously hospitalised in the same hospital due to mental illness.

\section{Discussion}

The people described here exemplify the dilemma between, on the one hand, the will and obligation to help the needy, ill person and on the other, the need to respect his wishes to live his life without intervention by external agencies. A conflict exists between respecting the person's autonomy and free will and the "good" paternalism of the therapist who takes care of, and makes decisions for, the mentally ill person who is incapable of knowing what is best for himself.

Patients who are severely ill and a danger to themselves, should be forcefully treated, but there are others who should be treated differently. Of course, the majority of patients would agree to treatment when offered appropriately and at the right time, but the professional staff occasionally finds this restricting, legal approach insufficient. It is very crucial to relate to the person's wishes and to honour them, regardless of that person's illness. But to speak about the free will of certain patients who are severely mentally ill, is incomprehensible. In such cases, lack of involuntary interventions may be a form of collusion with the patient's psychosis.

The first two individuals described could not be helped since they rejected help and no identifying information was attainable. The third man received involuntary psychiatric treatment only after the police intervened and identified him as being possibly dangerous to himself. The experience of former hospitalisation, if traumatic 
memories remained, might explain his refusal to return to the hospital.

These individuals chose to live in or near the community but were estranged from it. They did not demand anything from the community but whether or not they were needy could not be determined. The law authorises an involuntary psychiatric examination when there is fear that the person might be a danger to himself but the district psychiatrist (who has the power, in Israel, for forced psychiatric investigation) will not send his staff to bring an unknown person in for examination. (Psychiatric staff will not be sent to bring in the "man on the third park bench".)

In Mr Y's case, even his whereabouts were unknown from night to night. The police may detain a person who has committed a crime, regardless of his refusal to identify himself, but these people behave lawfully.

The question then arises whether this is a social or mental health problem. Is this social deviance, socially accepted self expression or an emotional pathology expressing itself in such a deviance? If someone chooses to be "anonymous" shouldn't we respect his decision? What if behind his anonymity hides his illness?

Whether someone would freely choose to become homeless, living off scraps of garbage and exposed to extreme weather conditions is debatable, but if the mentally ill person is "burnt out" and cannot take care of himself, should we not provide him with help, even against his own will, until his strength and mental health are restored? The patient's rights and his needs should be weighed against each other. ${ }^{11}$

Sometimes, our multidisciplinary staff feel that words and phrases such as "autonomy" and "free will" are far from the reality we see on the streets. The case of Mrs B, a homeless woman who was brought in for psychiatric treatment, with no diagnosis, no knowledge of her mental capacity, is exemplary. ${ }^{12}$ It is interesting to note that she did not identify herself immediately, but provided a false name, similar to our case of $\mathrm{Mr} \mathrm{Z}$. The treatment of the homeless mentally ill is more difficult when there are chemical abuse problems, ${ }^{13}$ criminal activity ${ }^{14}$ and medication non-compliance. ${ }^{15}$

There is a need for a change in the psychiatric services for this population. They should be more diverse and open in approaching this isolated group ${ }^{16}$ with outreach projects such as a streetlevel approach. ${ }^{17}$ Sometimes there is a need for non-governmental agencies, which are trusted more easily by the homeless. Organising a group of citizen volunteers or a self-help group, perhaps including former homeless persons, might encourage the homeless to participate.
Our cases illustrate that where there is an intractable problem of anonymity, talk of unabridged rights excusing obligation is practically nonsensical. We suggest that in questionable cases, when all other efforts have been made and the patient continues living on the street, a multidisciplinary team be given the authority to bring the patient to a general hospital emergency room where his physical, mental health and social needs can be evaluated.

Psychiatric examination, hospitalisation and drug treatment are not the only solutions. The mentally ill homeless can be given clothes, blankets, food or money, thereby facilitating a therapeutic relationship. Discussion of possibilities to provide the homeless with a home, supportive treatment ${ }^{18}$ or a therapeutic family ${ }^{19}$ may be undertaken after preliminary examination and clarification.

A contradiction exists between these philosophical questions and the feeling of the therapist that action must be taken. We do not feel at ease in discussing this matter in our warm academic rooms while the homeless remain in the cold streets. If society will change and modify the law and regulations, fewer homeless people will suffer or die in the cold.

Yuval Melamed, MD, is the Head of Open Department at Abarbanel Mental Health Center (Affiliated with Tel Aviv Faculty of Medicine), Bat Yam, Israel 59100. Dafna Fromer, MSW, is a Teacher in the School of Social Work, Tel Aviv University, Tel Aviv, Israel. Ziona Kemelman, MSW, is the Head of the Homeless Unit, Department of Social Services, Tel Aviv Municipality, Tel Aviv, Israel. Yoram Barak, $M D$, is the Head of the Psychogeriatric Department in the Abarbanel Mental Health Center and Psychiatric Consultant in the Homeless Unit, Department of Social Services, Tel Aviv Municipality, Tel Aviv, Israel.

\section{References}

1 Raps A, Kemelman Z. The fourth world - the homeless. Harefuah 1994;127:95-101.

2 Rosenheck R, Lam JA. Homeless mentally ill clients' and providers' perceptions of service needs and clients' use of services. Psychiatric Services 1997;48:381-6.

3 Wuerker AK, Keenan CK. Patterns of psychiatric service use by homeless mentally ill clients. Psychiatric Quarterly 1997;68: 101-16.

4 Pollio DE, North CS, Thompson S, Paquin JW, Spitznagel EL. Predictors of achieving stable housing in a mentally ill homeless population. Psychiatric Services 1997;48:528-30.

5 Scott J. Homelessness and mental illness. The British fournal of Psychiatry 1993;162:314-24

6 Marcos LR, Cohen NL, Nardacci D, Brittain J. Psychiatry takes to the streets: the New York City initiative for the homeless mentally ill. The American fournal of Psychiatry 1990;147: 1557-61.

7 Cohen CI, Thompson KS. Homeless mentally ill or mentally ill homeless? The American fournal of Psychiatry 1992;149:816-23.
her 
8 Abdul Hamid W, Wykes T, Stansfeld S. The homeless mentally ill: myths and realities. International Fournal of Social Psychiatry 1993;39:237-54

9 LaFond JQ. Law and the delivery of involuntary mental health services. American fournal of Orthopsychiatry 1994;64:209-15.

10 Kapp MB. Treatment and refusal rights in mental health: therapeutic justice and clinical accommodation. American fournal of Orthopsychiatry 1994;64:223-34.

11 Blecher JR. Rights versus needs of homeless mentally ill persons. Social Work 1988;33:398-402.

12 Cournos F. Involuntary medication and the case of Joyce Brown. Hospital and Community Psychiatry 1989;40:736-40.

13 Nuttbrock LA, Rahav M, Rivera JJ, Ng-Mak DS, Link BG. Outcomes of homeless mentally ill chemical abusers in Outcomes of homeless mentally ill chemical abusers in
community residences and a therapeutic community. Psychiatric Services 1998;49:68-76.

14 Stovall JG, Cloninger L, Appleby L. Identifying homeless men- tally ill veterans in jail: a preliminary report. Fournal of the American Academy of Psychiatry and the Law 1997;25:311-15.

15 Dixon L, Weiden P, Torres M, Lehman A. Assertive community treatment and medication compliance in the homeless mentally ill. The American fournal of Psychiatry 1997; 154:1302-4.

16 Jones A, Scannell T. Outreach interventions for the homeless mentally ill. British fournal of Nursing 1997;6:1236-8.

17 Rowe M, Hoge MA, Fisk D. Services for mentally ill homeless persons: street-level integration. American fournal of Orthopsychiatry 1998;68:490-6.

18 Kantor AS. Homeless but not helpless: legal issues in the care of homeless people with mental illness. Fournal of Social Issues 1989;45:91-104.

19 Ludwig EV. The mentally ill homeless: evolving involuntary commitment issues. Villanova Law Review 1991;36:1085-1111.

\section{News and notes}

\section{The Annual Intensive Course on Medical Ethics}

The Annual Intensive Course on Medical Ethics will be held from $11-15$ September, 2000 at the Wolfson Conference Centre, Imperial College Hammersmith Hospital Campus, London.

The course provides a stimulating multidisciplinary introduction to philosophical medical ethics for medical and nursing teachers, medical practitioners, members of ethics committees and administrators. It is organised in collaboration with the Institute of Medical Ethics. Lectures/ seminars, and small and large groups are led by leading international authorities in the field of medical ethics. PGEA and CME accreditation sought for 2000. (All previous courses have received full-range 10 session PGEA accreditation and $25 \mathrm{CME}$ credits).

For further details, please contact: Bang Nong on Tel:+44 (0)20 75946882 or Hersha Mistry on Tel:+44 (0)20 7594 6884, Centre for Continuing Education, Imperial College, Room 526 Sherfield Building, London SW7 2AZ. Fax: +44 (0)20 7594 6883; Email: cpd@ic.ac.uk; http://www.ad.ic.ac.uk/ $\mathrm{cpd} /$ medeth.htm

\section{News and notes}

\section{Secretary-General of CIOMS retires}

After 25 years of distinguished service as SecretaryGeneral of the Council for International Organisations of Medical Sciences (CIOMS), Dr Zbigniew Bankowski has retired. Formerly a WHO staff member, Dr Bankowski served initially as the Responsible Officer for Research Coordination and the Programme for Research Training and Grants. He subsequently served as WHO representative to Tunisia, a post which he combined with a Visiting Professorship of Histology in the Faculty of Medicine of Tunis.

In December 1999, CIOMS, which was created jointly by UNESCO and WHO in 1949, organised an International Conference on Pharmacovigilance and Related Ethical Issues, held in WHO and designed to mark its 50th anniversary.

Dr Bankowski has been elected SecretaryGeneral Emeritus of CIOMS, and to highlight his many eminent contributions to the work of CIOMS, in such areas as drug safety and bioethics/health care ethics, his many colleagues, friends and admirers have established a Zbigniew Bankowski Lecture Fund, intended to cover the costs of an annual lecture.

The fund will support a Zbigniew Bankowski Lecture on ethical aspects of health policy, to be given approximately once a year at a CIOMS conference by an eminent participant in that event. The distinction of being selected as Bankowski Lecturer will carry with it a special honorarium, and the lecture will be published in the conference proceedings as the Zbigniew Bankowski Lecture. The selection of the Lecturer will be made by the planning committee for each particular conference. 